https://helda.helsinki.fi

\title{
Addiction-related interactions of pregabalin with morphine in mice and humans : reinforcing and inhibiting effects
}

\section{Vashchinkina, Elena}

2018-05

Vashchinkina, E, Piippo , O, Vekovischeva , O, Krupitsky, E, llyuk, R, Neznanov, N , Kazankov , K , Zaplatkin , I \& Korpi , E R 2018 , ' Addiction-related interactions of pregabalin with morphine in mice and humans : reinforcing and inhibiting effects ' , Addiction Biology , vol. 23 , no. 3 , pp. 945-958 . https://doi.org/10.1111/adb.12538

http://hdl.handle.net/10138/325279

https://doi.org/10.1111/adb.12538

acceptedVersion

Downloaded from Helda, University of Helsinki institutional repository.

This is an electronic reprint of the original article.

This reprint may differ from the original in pagination and typographic detail.

Please cite the original version. 
Addiction-related interactions of pregabalin with morphine in mice and humans: reinforcing and inhibiting effects

Elena Vashchinkina ${ }^{*}$, Ossi Piippo ${ }^{1}$, Olga Vekovischeva ${ }^{1}$, Evgeny Krupitsky², Ruslan Ilyuk², Nikholai Neznanov², Kirill Kazankov³, Igor Zaplatkin ${ }^{3}$, and Esa R. Korpi ${ }^{1}$

${ }^{1}$ Department of Pharmacology, Faculty of Medicine, Haartmaninkatu 8, FI00014 University of Helsinki, Helsinki, Finland

2 Department of Addictions, St.-Petersburg Bekhterev Research

Psychoneurological Institute, ul. Bekhtereva 3, 192019, St.-Petersburg, Russian Federation

${ }^{3}$ Murmansk Regional Addiction Hospital, Verkhne-Rostinskoe shosse 17A, 183036, Murmansk, Russian Federation

${ }^{*}$ Correspondence to:

Dr. Elena Vashchinkina

Department of Pharmacology, Faculty of Medicine, Haartmaninkatu 8, FI00014 University of Helsinki, Helsinki, Finland, Tel: +358 (29)41 25367. Fax: +358 (29)41 25302, elena.vashchinkina@helsinki.fi 


\section{ABSTRACT}

The gabapentinoid pregabalin is a rapid-acting anxiolytic and analgesic, possibly suitable in supervised opioid detoxification. However, clinicians have been cautious using it because of its unknown addictive risk and rising number of mortalities after pregabalin self-medication in opioid abusers. Here, we studied interactions of pregabalin and morphine on reward functions of the dopamine (DA) system in mice and the efficacy of pregabalin on withdrawal in opioid addicts. After the treatment of mice with pregabalin and morphine, we used electrophysiology to study neuroplasticity in midbrain slices, selfadministration and conditioned place preference tests to investigate the rewarding potential of pregabalin, and naloxone-precipitated morphine withdrawal to evaluate opioid withdrawal symptoms. Further, we ran a pilot single-blind, randomized, controlled trial (34 heroin addicts) to evaluate the efficacy and safety of pregabalin in the treatment of opioid withdrawal syndrome. Pregabalin alone did not induce glutamate receptor neuroplasticity of DA neurons in the ventral tegmental area (VTA), but pretreatment with pregabalin suppressed morphine-induced neuroplasticity, hyperlocomotion and morphine self-administration. Pregabalin administration after chronic morphine exposure failed to induce any rewarding effects. Instead, pregabalin suppressed withdrawal symptoms in both morphine-treated mice and opioid addicts, and was well tolerated. Intriguingly, pregabalin administration after a low dose of morphine strongly facilitated VTA neuroplasticity and led to increased conditioned place preference. Pregabalin appears to have the efficacy to counteract both reinforcing and withdrawal effects of opioids, but it also has a potentiating effect when given to mice with existing opioid levels. 
Keywords dopamine neuroplasticity, morphine, pregabalin, reward, withdrawal, detoxification 


\section{Introduction}

Opioid dependence is a complex chronic disorder that affects numerous brain systems leading to a range of physical, learning, and behavioral effects (Koob and Volkow, 2016). Currently approved treatment protocols for opioid dependence include several stages (supervised withdrawal, followed by opioid antagonist treatment) and require polydrug therapy to suppress various withdrawal symptoms in the beginning of treatment (Sigmon et al., 2012). Even with the most advanced and intensive treatment, patients show poor compliance and experience severe adverse effects (Collins et al., 2005). New treatment strategies which reduce the severity of withdrawal and make the initiation of antagonist therapy shorter, less symptomatic, and easier to manage are greatly needed.

Pregabalin (S-(+)-3-isobutyl $\gamma$-aminobutyric acid), a gabapentinoid compound, has become the first-line treatment of neuropathic pain and is recommended as a potential first-line treatment for generalized anxiety disorder, being one of the most effective and safe drugs to date (Bandelow et al., 2008; Kremer et al., 2016). Importantly, pregabalin shows a rapid onset of action, has no active metabolites and minimal hepatic metabolism: a profile that makes it easy to use in clinical practice (Buoli et al., 2017). Indeed, its simultaneous analgesic and anxiolytic effects and its pharmacokinetic profile could also be beneficial for the treatment of opioid withdrawal syndrome (Sigmon et al., 2012). However, only a few studies have investigated the efficiency of gabapentinoids in opioid withdrawal treatment (Freynhagen et al., 2016). 
Although pregabalin is structurally related to $\gamma$-aminobutyric acid, GABA, it does not act on $\mathrm{GABA}_{A}$ or $\mathrm{GABA}_{B}$ receptors, nor on GABA reuptake transporters (Lanneau et al., 2002; Li et al., 2011). Instead, it has a selectively high affinity to an auxiliary $\alpha 2 \delta$ subunit of presynaptic voltage-gated $\mathrm{Ca}^{2+}$ channels (Taylor et al., 2007). Through this interaction with the $\alpha 2 \delta$ subunit, pregabalin attenuates $\mathrm{Ca}^{2+}$ influx into cells, and thereby suppresses $\mathrm{Ca}^{2+}-$ dependent presynaptic release of various neurotransmitters, including glutamate, noradrenaline and substance P (Dooley et al., 2000; Field et al., 2006; Taylor et al., 2007). Furthermore, another gabapentinoid, gabapentin, suppresses synaptogenesis and the trafficking of $\mathrm{Ca}^{2+}$ channels to the cell surface, in line with the interference of functions of the $\alpha 2 \delta$ subunits (Bauer et al., 2009; Eroglu et al., 2009). Autoradiography has shown high-affinity binding in the cortex, olfactory bulb, hypothalamus, amygdala, and hippocampus, and to a lesser extent in the ventral tegmental area (VTA) (Bian et al., 2006; Taylor et al., 2007). Functional magnetic resonance imaging has detected that pregabalin influences the activation of the insula and locus coeruleus, brain regions which play important roles in anxiety and opioid withdrawal (Aupperle et al., 2011; Koob, 2008; Takeuchi et al., 2007).

Importantly, although no systematic assessment of pregabalin's effects on reward mechanisms exists (Andrews et al., 2001; Chiappini and Schifano, 2016), recent animal studies and human case reports have suggested that pregabalin might be beneficial in treating opioid withdrawal. In fact, pregabalin suppressed naloxone-precipitated opioid withdrawal signs in a dosedependent manner in morphine-treated rats without preventing analgesic morphine tolerance (Hasanein and Shakeri, 2014; Jokinen et al., 2015). A 
case study reported that pregabalin ameliorated withdrawal signs within a week in an opiate user with a history of multiple unsuccessful detoxifications (Kammerer et al., 2012). It should also be noted that, recently, pregabalin has frequently been used by opioid abusers seeking self-detoxification (Wilens et al., 2015).

Nonetheless, clinicians are concerned about treating drug abusers with pregabalin because of its potential addictive risk. Pregabalin has been reported to produce a euphoric state and misuse in some patients with a history of opioid use (Grosshans et al., 2013), and, moreover, the number of deaths attributed to the combination of pregabalin and opioids has recently risen (Hakkinen et al., 2014). This may be due to the fact that pregabalin at unknown instances produces benzodiazepine-like effects and acts as an opioid booster (Ojanpera et al., 2016; Pesonen et al., 2011). Importantly, in rats, co-administration of morphine and pregabalin did not produce changes in brain concentrations of morphine, its major metabolites or pregabalin (Jokinen et al., 2015), indicating that there are no pharmacokinetic interactions between pregabalin and opioids. The conditions and underlying mechanisms of the pharmacodynamic interactions of pregabalin and opioids in opioid users and in mouse addiction models have not been investigated.

We report here a detailed analysis of the effects of pregabalin on the dopamine reward system in acute experiments and after long-term morphine exposure in mice. We further model the conditions resulting in an increase of reinforcing properties of pregabalin. We also report the results of a pilot randomized single-blind trial to assess the efficacy and safety of pregabalin treatment of opiate withdrawal. 


\section{Materials and methods}

\section{Preclinical studies}

\section{Animals and in vivo manipulations}

We used juvenile (22-30 days old) male and female transgenic TH-EGFP mice (Gong et al., 2003) for electrophysiology, and adult (8-11 weeks old) male C57BL/6JCrl mice (Charles River Germany, Sulzfield, Germany) for behavioral studies. All drug injections (s.c., i.v., or i.p.) and behavioral tests were performed between 08:00 and 19:00, with lights on between 6:00 and 18:00. All animal work was conducted according to relevant national and international guidelines. Animal experiments were authorized by the national Animal Experiment Board in Finland (Eläinkoelautakunta, ELLA).

\section{Electrophysiological experiments}

The TH-EGFP mice were decapitated $24 \mathrm{~h}$ after the treatment, between 9:00 and 13:00. Patch-clamp recordings from VTA DA neurons ex vivo from horizontal midbrain slices were performed essentially as previously described (Vashchinkina et al., 2012). Evoked excitatory postsynaptic currents (EPSCs) were recorded in the presence and absence of an N-methyl-D-aspartate receptor (NMDAR) blocker, D-(-)-2-amino-5-phosphonopentanoic acid (AP5, $50 \mu \mathrm{M})$, to obtain $\alpha$-amino-3-hydroxy-5-methyl-4-isoxazole propionic acid receptor (AMPAR) and AMPAR + NMDAR -mediated currents, respectively. The AMPA/NMDA ratio was calculated by dividing the peak amplitude of the AMPA receptor current with that of the NMDA receptor current, averaged from 18 EPSCs. The weighted decay time constant (tau, $\tau \mathrm{W})$ of the NMDAR 
EPSCs at $+40 \mathrm{mV}$ was calculated by fitting a double exponential function to each average EPSC and using the following formula: $\tau \mathrm{W}=[(\mathrm{A} 1 \times \tau 1)+(\mathrm{A} 2 \times$ $\tau 2)] /(\mathrm{A} 1+\mathrm{A} 2)$, where $\mathrm{A} 1$ and $\mathrm{A} 2$ are the amplitudes and $\tau 1$ and $\tau 2$ are the decay time constants of the fast and slow components, respectively (Barth and Malenka, 2001). For additional information, see the Supplementary information.

\section{Behavioral experiments}

\section{In vivo drug treatments with mice}

For acute experiments, mice were pretreated with pregabalin (50-200 mg/kg, i.p.) or its vehicle, and 30 min later they were treated with morphine (1-10 $\mathrm{mg} / \mathrm{kg}$, s.c.), or vice versa (treatment protocols in Figures 2 and 5). For chronic experiments, mice were treated with escalating doses of morphine (s.c.) every $16 \mathrm{~h}$ over a period of 4 weeks. One week after the last morphine injection, the mice were tested for conditioned place preference (CPP) and 3 weeks after the last morphine injection, for intravenous self-administration of pregabalin (treatment protocol in Figure 4). The morphine dose was increased as follows: $10-20 \mathrm{mg} / \mathrm{kg}$ on week $1,20-30 \mathrm{mg} / \mathrm{kg}$ on week $2,30-40 \mathrm{mg} / \mathrm{kg}$ on week 3 and $50-70 \mathrm{mg} / \mathrm{kg}$ on week 4 . Each week, the dose of morphine was increased by $10 \mathrm{mg} / \mathrm{kg}$, when the mice developed tolerance to the previous dose, assessed as a blunting of the morphine-induced hyperactivity in comparison to previous doses. Two independent batches of mice were tested.

\section{Spontaneous locomotor activity}

Mouse locomotor activity was analyzed by video-tracking software Ethovision 
XT (Version 10.1, Noldus Information Technology, Wageningen, the Netherlands) for $90 \mathrm{~min}$ in $19 \times 36 \mathrm{~cm}$ cages (Vashchinkina et al., 2012). Distances travelled during successive 15-min periods were calculated and compared between the treatments.

\section{Conditioned place preference}

The biased place conditioning paradigm consisted of 15-min pre-conditioning, 30-min conditioning, and 15-min post-conditioning periods, as previously described (Vekovischeva et al., 2004). Conditioning training was performed over 4 days: morning conditioning with the vehicle and evening conditioning with the drugs. The difference ("timeshift") in time spent on the initially nonpreferred material during pre-conditioning and post-conditioning tests was calculated as a measure of CPP. For additional information, see the Supplementary information.

\section{Intravenous drug self-administration}

The drug self-administration procedure, based on voluntary nose-poking activity of the mice, was carried out as previously described (Vashchinkina et al., 2012). Briefly, employing the yoked-control paradigm, each nose-poke resulted in a simultaneous infusion ( $1.7 \mu \mathrm{l}$; duration $1 \mathrm{~s})$ of pregabalin (5 $\mathrm{mg} / \mathrm{ml})$ or morphine $(1 \mathrm{mg} / \mathrm{ml})$ via the tail vein to both active and yoked-control mice. Mice were allowed to self-administer drugs for $20 \mathrm{~min}$. As a measure of reinforcement, the $\mathrm{R}$ factor was calculated (Vashchinkina et al., 2012). For detailed information, see the Supplementary information. 


\section{Naloxone-precipitated morphine withdrawal}

Mice were treated with escalating daily doses of morphine $(8-45 \mathrm{mg} / \mathrm{kg}, \mathrm{s.c}$.) for 5 days, with injections at 8:00 and 18:00 (Suzuki et al., 1996). Withdrawal symptoms were precipitated by injecting naloxone ( $3 \mathrm{mg} / \mathrm{kg}$, s.c.) $2 \mathrm{~h}$ after the last administration of morphine on the morning of Day 5 (treatment protocol in Figure 3). Pretreatment with pregabalin (50 mg/kg) occurred $30 \mathrm{~min}$ prior to naloxone injections. After the naloxone precipitation, mice were immediately placed in an acrylic cylinder (30 cm high, $20 \mathrm{~cm}$ in diameter). The number of jumps, exploratory rears, and forepaw tremor behaviors were counted for 30 min after the naloxone injection.

\section{Clinical study}

A six-day single-blind, randomized, controlled trial evaluated the efficacy of pregabalin in the detoxification of patients with opioid use disorder assigned to the inpatient withdrawal program. We randomly assigned 34 adult patients (details in Table1) diagnosed with heroin dependence (ICD-10) to either 600 $\mathrm{mg} /$ day of pregabalin or $600 \mu \mathrm{g} /$ day of clonidine (an $\alpha 2$ adrenoceptor agonist) using a random number generator method (Figure 1). Participants also received $30 \mathrm{mg}$ of doxylamine (a sedative antihistamine) daily and other symptom-triggered symptomatic therapy (Table S1). The study was conducted at two sites in Russia and registered at ClinicalTrials.gov, NCT03017430. Results of the trial have been partially reported in a Russian language journal (Krupitsky et al., 2016).

The primary outcome was completion of the withdrawal treatment program as defined by standard physician-rated and patient-rated quantitative 
psychometric scales. The secondary outcomes were: amount of symptomtriggered medications administered (NSAIDs), severity of withdrawal symptoms (efficacy), and number of reported adverse events using daily selfreports and diverse clinical scales (safety). For additional information, see the Supplementary information.

\section{Drugs}

For mouse studies, morphine hydrochloride powder and pregabalin capsules (Lyrica, Pfizer, New York City, NY, USA) were purchased from the University Pharmacy (Helsinki, Finland). The morphine was dissolved in saline and injected s.c. in a volume of $10 \mathrm{ml} / \mathrm{kg}$. The morphine concentrations are given as free base per unit of volume. Pregabalin was dissolved in $0.5 \%$ methylcellulose in physiological saline and administered i.p. in a volume of 10 $\mathrm{ml} / \mathrm{kg}$. For i.v. administration, pregabalin (Tocris Bioscience, Bristol, UK) was dissolved in saline.

For the clinical trial: pregabalin capsules (Lyrica, Pfizer, New York City, NY, USA), clonidine tablets (Clopheline, Organica, Novokuznetsk, Russia), doxylamine tablets (Donormyl, UPSA SAS, Agen, France), an NSAID, ketorolac (Ketanove, Ranbaxy, Dewas, India), bromdihydrochlorphenylbenzodiazepine (Phenazepam, Valenta Pharm, Schyolkovo, Russia), metoclopramide (Cerucal, Teva Pharmaceutical Industries, Godollo, Hungary), loperamide (Imodium, Johnson \& Johnson, Catalent UK Swindon Zydis Ltd., Swindon, UK), naphazoline (Naphthyzin, Sintez, Kurgan, Russia, or Sanorin, Teva Pharmaceutical Industries, OpavaKomarov, Czech Republic) were administered to participants. 


\section{Statistical analyses}

The results are presented as means \pm SEM. Data were statistically analyzed using the IBM SPSS Statistics 21 software (IBM, Armonk, New York, NY, USA). Preclinical studies were analyzed using one-way or two-way ANOVAs followed by a Bonferroni test or unpaired Student's $t$-tests $(p<0.05)$. The clinical study was analyzed using the intention-to-treat approach. The primary outcome was analyzed using Mantel-Cox log rank and Kaplan-Meier survival curves, and secondary outcomes either by Fisher's exact test for categorical endpoints or by repeated ANOVA followed by a Bonferroni test.

\section{Results}

Acute pregabalin inhibited morphine-induced hyperlocomotion, selfadministration, VTA DA-neuron neuroplasticity, and morphine withdrawal symptoms

Pretreatment with pregabalin dose-dependently attenuated morphine-induced hyperlocomotion (Figure 2A; pretreatment effect: $\mathrm{F}_{3,57}=5.7, p<0.01$ ). Pregabalin alone at doses of 50-200 mg/kg (i.p.) did not alter locomotor activity in mice, compared to the vehicle $\left(\mathrm{F}_{3,22}=0.3, p=0.8\right)$.

We then tested whether pregabalin altered the reinforcing properties of morphine. Using acute i.v. self-administration, we found that the nose-poking for morphine and the morphine intake during the session, at an infused concentration known to be self-administered by mice (Kuzmin et al., 1997), 
were significantly attenuated by pretreatment with pregabalin $(50 \mathrm{mg} / \mathrm{kg}$, i.p.) (Figure 2B-C). Pregabalin infusion did not sustain any enhanced nose-poking behavior.

We also determined whether the pretreatment with pregabalin affects morphine-induced neuroplasticity in VTA DA neurons (Ungless et al., 2001; Vashchinkina et al., 2012). The morphine-induced increase in the AMPA/NMDA ratio in the VTA DA neurons $24 \mathrm{~h}$ after the single morphine dose (10 mg/kg, s.c.) was suppressed by pregabalin (50 mg/kg, i.p.) given 30 min before the morphine (Figure 2D; pretreatment effect: $F_{3,27}=5.4, p<0.01$ ). The weighted decay time constants $(\tau \mathrm{W})$ of the NMDAR EPSCs were similar for all groups (treatment factor: $F_{3,36}=2.3, p=0.09 ; \tau \mathrm{W}$ given as mean \pm SEM: vehicle, $58 \pm 6 \mathrm{~ms}$; morphine (10 mg/kg), $74 \pm 4 \mathrm{~ms}$; pregabalin (50 $\mathrm{mg} / \mathrm{kg}), 58 \pm 6 \mathrm{~ms} ;$ pregabalin $(50 \mathrm{mg} / \mathrm{kg})+$ morphine $(10 \mathrm{mg} / \mathrm{kg}), 72 \pm 6 \mathrm{~ms})$.

We next asked whether a single injection of pregabalin is sufficient to suppress morphine withdrawal in mice. To address this question, we injected pregabalin $(50 \mathrm{mg} / \mathrm{kg})$ or vehicle $30 \mathrm{~min}$ prior to precipitation of withdrawal symptoms with naloxone $(3 \mathrm{mg} / \mathrm{kg}$ ) in subchronically morphine-treated mice (Figure 3). Pregabalin pretreatment significantly attenuated withdrawal signs, defined as jumps and tremor episodes, compared to vehicle pretreatment (Figure 3 , $t$-test, $p<0.05)$. The number of rears remained similar in both pretreatment groups.

Together, these results suggest that pregabalin alone is insufficient to induce rewarding behavior, but that, when used as a pretreatment, it effectively attenuates voluntary intake of morphine, morphine-induced 
neuroplasticity in the VTA, and withdrawal symptoms from subchronic morphine treatment in mice.

\section{Past long-term morphine exposure failed to alter the rewarding effects of pregabalin}

Taking into account several reports regarding the misuse of pregabalin in subjects with an opiate history (Grosshans et al., 2013), we tested whether long-term morphine exposure modifies the rewarding properties of pregabalin. To address this, mice were treated with escalating doses of morphine for four weeks, one week thereafter they were subjected to place conditioning with pregabalin, and again one week later the mice were given access to acute i.v. self-administration of pregabalin (Figure 4A).

Expectedly, morphine-exposed mice lost weight (Figure 4A, $t$-test, $p<$ 0.01), and they showed lower locomotor activity during the morning vehicleconditioning sessions as compared to the morphine-naïve group (Figure 4C, morphine exposure $\times$ pregabalin dose interaction: $F_{1,39}=4.0, p=0.05$ ).

However, morphine-exposed mice showed significant sedation after the higher pregabalin dose $(100 \mathrm{mg} / \mathrm{kg})$ during pregabalin-conditioning sessions (Figure 4C, morphine exposure $\times$ pregabalin dose interaction: $F_{1,39}=4.9, p=$ $0.03)$, but the timeshifts during preference testing remained similar between the groups (Figure 4B-C, morphine exposure effect: $F_{1,39}=0.01, p>0.05$ ).

One week after the CPP test, these mice were tested regarding voluntary i.v. pregabalin self-administration. Noteworthy, morphine-exposed mice had similar nose-poking activity as the control mice (Figure 4D, $t$-test, $p$ 
$>0.05)$. During 20-min sessions, both groups self-administered the same amount of pregabalin (Figure 4E-F, $t$-test, $p>0.05$ ). In conclusion, we found that both place conditioning and pregabalin self-administration were not affected by morphine exposure history. The morphine-experienced mice were slightly more sensitive to sedation by pregabalin than the control mice, but no clear rewarding effects of pregabalin were detected in either group.

\section{Low doses of morphine followed by pregabalin provoked plasticity in VTA DA neurons and place preference}

The fact that pregabalin acts on "overexcited" synapses (Dooley et al., 2000; Fehrenbacher et al., 2003) led us to hypothesize that administration of pregabalin after morphine may more robustly suppress the effects of morphine than when given in the reverse order. To test this idea, mice were first pretreated with morphine (1-10 $\mathrm{mg} / \mathrm{kg}$, s.c.), and then $30 \mathrm{~min}$ later they were treated with pregabalin (50 $\mathrm{mg} / \mathrm{kg}$, i.p.). Afterward, we studied the druginduced neuroplasticity in VTA DA neurons and place conditioning.

Consistent with previous reports (Saal et al., 2003), morphine dosedependently increased the AMPA/NMDA ratio in VTA DA neurons at $24 \mathrm{~h}$ after treatments (Figure 5A; morphine effect: $F_{3,30}=8.9, p<0.001$ ). To our surprise, the additional post-treatment with pregabalin $(50 \mathrm{mg} / \mathrm{kg})$ robustly potentiated the effect from the low doses of morphine $(1-3 \mathrm{mg} / \mathrm{kg})$, seen as an increase in the AMPA/NMDA ratio (Figure 5A; pregabalin effect: $F_{1,40}=8.9, p$ $<0.001)$. This is to be compared with the attenuation of morphine-induced neuroplasticity by pretreatment with pregabalin (see Figure 2D). 
We then examined whether the combination of low doses of morphine (1-3 $\mathrm{mg} / \mathrm{kg})$ with pregabalin post-treatment $(50 \mathrm{mg} / \mathrm{kg}$ ) also altered the reinforcing properties of morphine by studying the development of CPP (Figure 5B-E). In line with the neuroplasticity results, mice treated with morphine $(1 \mathrm{mg} / \mathrm{kg})$ followed by pregabalin post-treatment before each conditioning session showed significant positive timeshifts (preference) as compared to those post-treated with the vehicle (Figure 5B; treatment effect: $\left.F_{3,35}=8.5, p<0.001\right)$. Furthermore, the expression of place preference was significantly different $(p<0.05)$ from the group that had the opposite treatment regime: treatment with pregabalin and post-treatment with morphine $(1 \mathrm{mg} / \mathrm{kg})$ before conditioning failed to induce place preference (Figure 5B). During the conditioning sessions, only the morphine-pregabalin group showed some hyperlocomotion as compared to all other groups (Figure 5D; treatment effect: $\left.F_{3,28}=16.7, p<0.01\right)$.

A small increase of the morphine dose to $3 \mathrm{mg} / \mathrm{kg}$, however, eliminated the difference in the timeshifts induced by pregabalin post-treatment: morphine alone, morphine-pregabalin and pregabalin-morphine regimes all induced identical timeshifts (Figure 5C; treatment effect: $F_{3,35}=8.5, p<$ 0.001). This dose of morphine also strongly induced locomotor activity during conditioning sessions as compared to the lower dose (Figure 5C-E; treatment effect: $\left.F_{3,28}=33.5, p<0.001\right)$.

\section{Pregabalin suppressed opioid withdrawal in human subjects}


To translate part of the preclinical data presented above to clinical conditions, we ran a pilot study of the efficacy and safety of pregabalin in the treatment of opioid withdrawal syndrome (Figure 1). The groups did not differ in their clinical characteristics (Table 1). Among the pregabalin group, 15 of 19 patients $(79 \%)$ completed the 6 -day treatment, whereas only 7 of 15 patients $(47 \%)$ of the clonidine group did (Fisher's exact test, $p=0.05$ ). Kaplan-Meier survival analysis further confirmed the better patient retention in the pregabalin group (Figure 6A; Log Rank (Mantel-Cox) criterion, $p=0.001$ ). Overall changes of opioid withdrawal severity remained similar in both treatment groups, probably due to the symptom-triggered study design (Figure 6H-J; treatment effect: $\mathrm{F}_{1,5}<0.9, p>0.05$ ).

The pregabalin group reported better well-being (Figure 6B; treatment effect: $F_{1,5}=4.8, p=0.03$ ) and lower scores for opioid cravings (Figure $6 \mathrm{E}$; treatment effect: $\mathrm{F}_{1,5}=3.7, p=0.05$ ), depression (Figure 6F; treatment effect: $F_{1,5}=5.4, p=0.02$ ) and anxiety (Figure 6G; treatment effect: $F_{1,5}=3.7, p=$ 0.057). Furthermore, the average dose of symptom-triggered ketorolac in the pregabalin group was almost half of that in the clonidine group (Figure 6D; $t$ test, $p=0.04)$. While the total rate of adverse events was similar in both groups (about $73 \%$ of patients), the pregabalin group reported less fatigue, lack of energy and asthenia ( $16 \%$ vs. $47 \%$; Fisher's exact test, $p<0.05)$. Taken together, reduced cravings, fatigue and analgesic requirements in the pregabalin-treated patients indicate improved efficacy and tolerability of the pregabalin-based approach in the treatment of opioid withdrawal compared to the clonidine-based one, resulting in a higher rate of completion of the 
detoxification program. No serious or severe adverse events of pregabalin were noted in this study.

\section{Discussion}

The question of whether pregabalin is a safe drug, especially for drug abusers, is still debated. Case reports that advocate or criticize the use of pregabalin in opioid abusers provide little basis for scientific generalization. In the present study, we examined the addictive profile of pregabalin in mice, the effects of pregabalin and morphine combination in different addiction-related settings, and ran the first clinical trial on the efficacy and safety of pregabalin in 34 opiate abusers. The key issues that are necessary to consider when coadministering pregabalin and morphine appear to be the order and time of drug administration.

To our knowledge, there are no published data on possible interspecies differences in pregabalin-induced psychoactive/toxicity effects. A recent translational study (Lyndon et al., 2017) showed that, in mice, coadministration of pregabalin and morphine resulted in significantly greater respiratory depression than administrations of morphine or pregabalin separately. In the same study, heroin users reported that the combination of heroin and pregabalin often reinforced the effects of heroin, increasing the risk for an overdose. Another study in rats showed that pregabalin potentiated the antinociceptive and sedative effects of oxycodone and morphine without alterations in brain concentrations of opioids or pregabalin (Jokinen et al., 2015). Taken together, these data suggest that results from preclinical models 
can translate to human conditions in the study of the psychoactive/toxicity

effects of pregabalin and morphine.

We observed anti-addiction, protective efficacy of pregabalin on the development of morphine-induced neuroadaptations in VTA DA neurons, psychomotor activation (hyperlocomotion) and self-administration, when mice received pregabalin prior to morphine. Generally, that is in line with the effects of benzodiazepine pretreatment on the effects of morphine (Panhelainen et al., 2011), except for the fact that the doses of pregabalin used here did not induce sedation or glutamatergic synaptic plasticity, unlike the benzodiazepines (Heikkinen et al., 2009; Tan et al., 2011). The plasticity that morphine induces in VTA DA neurons is known to be dependent on NMDARs (Brown et al., 2010). Recent studies have demonstrated that pregabalin attenuates the levels of D-serine, an endogenous co-agonist of NMDARs, which leads to a shortening of the decay of NMDAR currents (Kato et al., 2016; Singh et al., 2013). This down-regulation of D-serine levels would suppress morphine-induced plasticity in VTA DA neurons. In fact, earlier reports have shown that the selective glycine/D-serine-site antagonist of the NMDAR, L-701,324, significantly suppresses morphine-induced CPP (Kotlinska and Biala, 1999). However, detailed post hoc analysis of the kinetics of the NMDAR-mediated EPSCs did not reveal significant differences in VTA DA neurons between control and pregabalin-pretreated groups; thus, the mechanism of the attenuation of morphine-induced neuroplasticity in VTA DA neurons remains unknown.

An important and unexpected finding was that pregabalin acted as an opioid booster when it was administered after an acute low dose of morphine 
in mice. This treatment schedule potentiated morphine-induced neuroplasticity ex vivo in VTA DA neurons and reward in the CPP test. Noteworthy, opioidantagonist pretreatment did not alter pregabalin effects on the animals' respiration (Lyndon et al., 2017), indicating that pregabalin action is not associated with a pregabalin-induced release of endogenous opioids or direct activation of opioid receptors.

Gabapentinoids, especially pregabalin, is often used clinically in neuropathic pain (Finnerup et al., 2015), with the idea that they might prevent the spinal neuroplasticity formation associated with neuropathy (Verma et al., 2014). Indeed, there are multiple effects of gabapentinoids, although their primary target of action and high-affinity binding site is on the $\alpha 2 \delta$ auxiliary subunit of $\mathrm{Ca}^{2+}$ channels (Taylor et al., 2007), which results in reduced trafficking of calcium channels to plasma membranes (Bauer et al., 2010). Other effects of gabapentinoids include the reduction of presynaptic neurotransmitter release (Taylor et al., 2007), the calming effect on hyperexcited glutamatergic synapses (Dooley et al., 2000; Fehrenbacher et al., 2003) and the suppression of new synapse formation via the thrombospondindependent mechanism (Eroglu et al., 2009). All of which may have contributed to the anti-addiction efficacy we detected in opioid selfadministration and the mesolimbic neuroplasticity and attenuation of opioid withdrawal symptoms. Since we also observed pro-addictive responses to opioids by post-treatment with pregabalin, the involvement of several neurotransmitters, rather than a simple summation of drug effects (e.g., disinhibition), needs to be considered in future studies. 
Most importantly, pregabalin treatment strongly attenuated opioid withdrawal symptoms in mice and retained the heroin addicts in detoxification treatment better than the treatment with clonidine, the positive control drug. Indeed, in our present pilot clinical trial, pregabalin treatment effectively suppressed withdrawal symptoms during the 6-day treatment without any serious adverse events. Furthermore, pregabalin-treated patients required less of the NSAID ketorolac during the trial. This decrease in the amount of analgesic drug requirement remains an important indicator of the efficiency of the pregabalin therapy, because it suggests a clear reduction in pain-related symptoms during opiate withdrawal when treated with pregabalin. Of note, there was a significant reduction by the pregabalin therapy over the clonidine control therapy on the scores for craving, anxiety and depression, and an increase in general well-being. Thus, these results are in line with recent case reports on pregabalin (Freynhagen et al., 2016) and a trial with gabapentin as an add-on to methadone-assisted detoxification (Salehi et al., 2011).

Despite recent reports of a rapid rise in the misuse of pregabalin, it is necessary to separate the cases of abuse of and dependence on pregabalin from, first, pseudoaddiction cases occurring because of inadequate pain treatment rather than drug dependence (Weissman and Haddox, 1989), and, second, from "off-label" cases of pregabalin use as a self-treatment of opiate withdrawal symptoms (Wilens et al., 2015). According to a recent systematic review, "pregabalin misuse or abuse may be limited to the population of individuals already predisposed to substance abuse, rather than this issue widely occurring in the general population" (Freynhagen et al., 2016). Our clinical and preclinical results, which show the lack of rewarding effects of 
pregabalin even after one month of chronic morphine exposure in mice, further narrow the size of the possible at-risk group.

In conclusion, our study provides additional evidence for the efficacy and safety of pregabalin-based treatment in opioid withdrawal in a controlled hospital setting. However, the risk of pro-addictive effects from pregabalin, when added to the ambient low-dose opioid effect, should promote measures preventing its use as self-medication in opioid users. 


\section{Acknowledgments and disclosures}

We thank Heidi Hytönen and Kristiina Dahl for skillful technical aid. This work was supported by the Academy of Finland (EV, OP, OV, ERK), the Sigrid Juselius Foundation (EV, OP, OV, ERK), and the Ministry of Health of Russian Federation (EK, RI, NN, KK, IZ).

The authors report no biomedical financial interests or potential conflicts of interest. 
Authors contribution:

EV, OP, OV, ERK and RI, NN, KK, IZ, EK were responsible for the study concept and design of preclinical and clinical parts, respectively. EV, OP, OV contributed to the acquisition of animal data. RI, KK, IZ and EK contributed to the acquisition of human data. EV, OP, OV, RI, KK, IZ, EK and ERK assisted with data analysis and interpretation of findings. EV drafted the manuscript. OV, NN, EK and ERK provided critical revision of the manuscript for important intellectual content. All authors critically reviewed content and approved final version for publication. 


\section{References}

Andrews N, Loomis S, Blake R, Ferrigan L, Singh L, McKnight AT (2001) Effect of gabapentin-like compounds on development and maintenance of morphine-induced conditioned place preference. Psychopharmacology (Berl) 157:381-387.

Aupperle RL, Ravindran L, Tankersley D, Flagan T, Stein NR, Simmons AN, Stein MB, Paulus MP (2011) Pregabalin influences insula and amygdala activation during anticipation of emotional images.

Neuropsychopharmacology 36:1466-1477.

Bandelow B, Zohar J, Hollander E, Kasper S, Moller HJ, Wfsbp Task Force on Treatment Guidelines for Anxiety O-C, Post-Traumatic Stress D, Zohar J, Hollander E, Kasper S, Moller HJ, Bandelow B, Allgulander C, AyusoGutierrez J, Baldwin DS, Buenvicius R, Cassano G, Fineberg N, Gabriels L, Hindmarch I, Kaiya H, Klein DF, Lader M, Lecrubier Y, Lepine JP, Liebowitz MR, Lopez-Ibor JJ, Marazziti D, Miguel EC, Oh KS, Preter M, Rupprecht R, Sato M, Starcevic V, Stein DJ, van Ameringen M, Vega J (2008) World Federation of Societies of Biological Psychiatry (WFSBP) guidelines for the pharmacological treatment of anxiety, obsessivecompulsive and post-traumatic stress disorders - first revision. World J Biol Psychiatry 9:248-312.

Barth AL, Malenka RC (2001) NMDAR EPSC kinetics do not regulate the critical period for LTP at thalamocortical synapses. Nat Neurosci 4:235236.

Bauer CS, Nieto-Rostro M, Rahman W, Tran-Van-Minh A, Ferron L, Douglas L, Kadurin I, Sri Ranjan Y, Fernandez-Alacid L, Millar NS, Dickenson AH, Lujan R, Dolphin AC (2009) The increased trafficking of the calcium channel subunit $\alpha 2 \delta-1$ to presynaptic terminals in neuropathic pain is inhibited by the $\alpha 2 \delta$ ligand pregabalin. J Neurosci 29:4076-4088.

Bauer CS, Rahman W, Tran-van-Minh A, Lujan R, Dickenson AH, Dolphin AC (2010) The anti-allodynic $\alpha 2 \delta$ ligand pregabalin inhibits the trafficking of the calcium channel $\alpha 2 \delta-1$ subunit to presynaptic terminals in vivo. Biochem Soc Trans 38:525-528.

Bian F, Li Z, Offord J, Davis MD, McCormick J, Taylor CP, Walker LC (2006) Calcium channel $\alpha 2 \delta$ type 1 subunit is the major binding protein for pregabalin in neocortex, hippocampus, amygdala, and spinal cord: an ex vivo autoradiographic study in $\alpha 2 \delta$ type 1 genetically modified mice. Brain Res 1075:68-80.

Brown MT, Bellone C, Mameli M, Labouebe G, Bocklisch C, Balland B, Dahan L, Lujan R, Deisseroth K, Luscher C (2010) Drug-driven AMPA receptor 
redistribution mimicked by selective dopamine neuron stimulation. PLoS One 5:e15870.

Buoli M, Caldiroli A, Serati M (2017) Pharmacokinetic evaluation of pregabalin for the treatment of generalized anxiety disorder. Expert Opin Drug Metab Toxicol 13(3):351-359.

Chiappini S, Schifano F (2016) A Decade of Gabapentinoid Misuse: An Analysis of the European Medicines Agency's 'Suspected Adverse Drug Reactions' Database. CNS Drugs 30:647-654.

Collins ED, Kleber HD, Whittington RA, Heitler NE (2005) Anesthesia-assisted vs buprenorphine- or clonidine-assisted heroin detoxification and naltrexone induction: a randomized trial. JAMA 294:903-913.

Dooley DJ, Donovan CM, Pugsley TA (2000) Stimulus-dependent modulation of $[(3) \mathrm{H}]$ norepinephrine release from rat neocortical slices by gabapentin and pregabalin. J Pharmacol Exp Ther 295:1086-1093.

Eroglu C, Allen NJ, Susman MW, O'Rourke NA, Park CY, Ozkan E, Chakraborty C, Mulinyawe SB, Annis DS, Huberman AD, Green EM, Lawler J, Dolmetsch R, Garcia KC, Smith SJ, Luo ZD, Rosenthal A, Mosher DF, Barres BA (2009) Gabapentin receptor $\alpha 2 \delta-1$ is a neuronal thrombospondin receptor responsible for excitatory CNS synaptogenesis. Cell 139:380-392.

Fehrenbacher JC, Taylor CP, Vasko MR (2003) Pregabalin and gabapentin reduce release of substance $P$ and CGRP from rat spinal tissues only after inflammation or activation of protein kinase C. Pain 105:133-141.

Field MJ, Cox PJ, Stott E, Melrose H, Offord J, Su TZ, Bramwell S, Corradini L, England S, Winks J, Kinloch RA, Hendrich J, Dolphin AC, Webb T, Williams D (2006) Identification of the $\alpha 2 \delta-1$ subunit of voltage-dependent calcium channels as a molecular target for pain mediating the analgesic actions of pregabalin. Proc Natl Acad Sci U S A 103:17537-17542.

Finnerup NB, Attal N, Haroutounian S, McNicol E, Baron R, Dworkin RH, Gilron I, Haanpaa M, Hansson P, Jensen TS, Kamerman PR, Lund K, Moore A, Raja SN, Rice AS, Rowbotham M, Sena E, Siddall P, Smith BH, Wallace M (2015) Pharmacotherapy for neuropathic pain in adults: a systematic review and meta-analysis. The Lancet Neurology 14:162-173.

Freynhagen R, Backonja M, Schug S, Lyndon G, Parsons B, Watt S, Behar R (2016) Pregabalin for the Treatment of Drug and Alcohol Withdrawal Symptoms: A Comprehensive Review. CNS Drugs 30:1191-1200.

Grosshans M, Lemenager T, Vollmert C, Kaemmerer N, Schreiner R, Mutschler J, Wagner X, Kiefer F, Hermann D (2013) Pregabalin abuse among opiate addicted patients. Eur J Clin Pharmacol 69:2021-2025. 
Hakkinen M, Vuori E, Kalso E, Gergov M, Ojanpera I (2014) Profiles of pregabalin and gabapentin abuse by postmortem toxicology. Forensic Sci Int 241:1-6.

Hasanein P, Shakeri S (2014) Pregabalin role in inhibition of morphine analgesic tolerance and physical dependency in rats. Eur J Pharmacol 742:113-117.

Heikkinen AE, Moykkynen TP, Korpi ER (2009) Long-lasting modulation of glutamatergic transmission in VTA dopamine neurons after a single dose of benzodiazepine agonists. Neuropsychopharmacology 34:290-298.

Jokinen V, Lilius TO, Laitila J, Niemi M, Rauhala PV, Kalso EA (2015) Pregabalin enhances the antinociceptive effect of oxycodone and morphine in thermal models of nociception in the rat without any pharmacokinetic interactions. Eur J Pain 20:297-306.

Kammerer N, Lemenager T, Grosshans M, Kiefer F, Hermann D (2012) [Pregabalin for the reduction of opiate withdrawal symptoms]. Psychiatr Prax 39:351-352.

Kato E, Matsuzawa R, Kobayashi S, Fukushima T, Maekawa M, Hori Y (2016) Effects of pregabalin on spinal D-serine content and NMDA receptormediated synaptic transmission in mice with neuropathic pain. Neurosci Lett 636:270-275.

Koob GF (2008) A role for brain stress systems in addiction. Neuron 59:11-34. Koob GF, Volkow ND (2016) Neurobiology of addiction: a neurocircuitry analysis. Lancet Psychiatry 3:760-773.

Kotlinska J, Biala G (1999) Effects of the NMDA/glycine receptor antagonist, $\mathrm{L}-701,324$, on morphine- and cocaine-induced place preference. Pol J Pharmacol 51:323-330.

Kremer M, Salvat E, Muller A, Yalcin I, Barrot M (2016) Antidepressants and gabapentinoids in neuropathic pain: Mechanistic insights. Neuroscience 338:183-206.

Krupitsky EM, llyuk RD, Mikhailov AD, Kazankov KA, Rybakova KV, Skurat EP, Grishina OG, Zaplatkin IA, Vetrova MV, Neznanov NG (2016) A randomized single blind study of the efficacy of pregabalin in the treatment of opioid withdrawal syndrome. Zh Nevrol Psikhiatr Im S S Korsakova 116:29-36.

Kuzmin AV, Semenova S, Gerrits MA, Zvartau EE, Van Ree JM (1997) Kappa-opioid receptor agonist $U 50,488 \mathrm{H}$ modulates cocaine and morphine self-administration in drug-naive rats and mice. Eur J Pharmacol 321:265271. 
Lanneau C, Harries MH, Ray AM, Cobb SR, Randall A, Davies CH (2002) Complex interactions between mGluR1 and mGluR5 shape neuronal network activity in the rat hippocampus. Neuropharmacology 43:131-140.

Li Z, Taylor CP, Weber M, Piechan J, Prior F, Bian F, Cui M, Hoffman D, Donevan S (2011) Pregabalin is a potent and selective ligand for $\alpha 2 \delta-1$ and $\alpha 2 \delta$-2 calcium channel subunits. Eur J Pharmacol 667:80-90.

Lyndon A, Audrey S, Wells C, Burnell ES, Ingle S, Hill R, Hickman M, Henderson $G$ (2017) Risk to heroin users of polydrug use of pregabalin or gabapentin. Addiction

Ojanpera I, Kriikku P, Vuori E (2016) Fatal toxicity index of medicinal drugs based on a comprehensive toxicology database. Int J Legal Med 130:12091216.

Panhelainen AE, Vekovischeva OY, Aitta-Aho T, Rasanen I, Ojanpera I, Korpi ER (2011) Diazepam-induced neuronal plasticity attenuates locomotor responses to morphine and amphetamine challenges in mice. Neuroscience 192:312-321.

Pesonen A, Suojaranta-Ylinen R, Hammaren E, Kontinen VK, Raivio P, Tarkkila P, Rosenberg PH (2011) Pregabalin has an opioid-sparing effect in elderly patients after cardiac surgery: a randomized placebo-controlled trial. Br J Anaesth 106:873-881.

Saal D, Dong Y, Bonci A, Malenka RC (2003) Drugs of abuse and stress trigger a common synaptic adaptation in dopamine neurons. Neuron 37:577-582.

Salehi M, Kheirabadi GR, Maracy MR, Ranjkesh M (2011) Importance of gabapentin dose in treatment of opioid withdrawal. J Clin Psychopharmacol 31:593-596.

Sigmon SC, Bisaga A, Nunes EV, O'Connor PG, Kosten T, Woody G (2012) Opioid detoxification and naltrexone induction strategies: recommendations for clinical practice. The American journal of drug and alcohol abuse 38:187-199.

Singh NS, Paul RK, Torjman MC, Wainer IW (2013) Gabapentin and (S)pregabalin decrease intracellular D-serine concentrations in PC-12 cells. Neurosci Lett 535:90-94.

Suzuki T, Tsuda M, Narita M, Funada M, Mizoguchi H, Misawa M (1996) Diazepam pretreatment suppresses morphine withdrawal signs in the mouse. Life Sci 58:349-357.

Takeuchi Y, Takasu K, Ono H, Tanabe M (2007) Pregabalin, S-(+)-3isobutylgaba, activates the descending noradrenergic system to alleviate 
neuropathic pain in the mouse partial sciatic nerve ligation model. Neuropharmacology 53:842-853.

Tan KR, Rudolph U, Luscher C (2011) Hooked on benzodiazepines: GABA receptor subtypes and addiction. Trends Neurosci 34:188-197.

Taylor CP, Angelotti T, Fauman E (2007) Pharmacology and mechanism of action of pregabalin: the calcium channel $\alpha 2 \delta$ subunit as a target for antiepileptic drug discovery. Epilepsy Res 73:137-150.

Ungless MA, Whistler JL, Malenka RC, Bonci A (2001) Single cocaine exposure in vivo induces long-term potentiation in dopamine neurons. Nature 411:583-587.

Vashchinkina E, Panhelainen A, Vekovischeva OY, Aitta-aho T, Ebert B, Ator NA, Korpi ER (2012) GABA site agonist gaboxadol induces addictionpredicting persistent changes in ventral tegmental area dopamine neurons but is not rewarding in mice or baboons. J Neurosci 32:5310-5320.

Weissman DE, Haddox JD (1989) Opioid pseudoaddiction - an iatrogenic syndrome. Pain 36:363-366.

Vekovischeva OY, Semenova SG, Verbitskaya EV, Zvartau EE (2004) Effects of morphine and cocaine in mice with stable high aggressive and nonaggressive behavioral strategy. Pharmacol Biochem Behav 77:235243.

Verma V, Singh N, Singh Jaggi A (2014) Pregabalin in neuropathic pain: evidences and possible mechanisms. Current neuropharmacology 12:4456.

Wilens T, Zulauf C, Ryland D, Carrellas N, Catalina-Wellington I (2015) Prescription medication misuse among opioid dependent patients seeking inpatient detoxification. The American journal on addictions / American Academy of Psychiatrists in Alcoholism and Addictions 24:173-177. 
Table 1. Demographics of participants and clinical characteristics of the pregabalin and clonidine groups

\begin{tabular}{lcc}
\hline Measure & Pregabalin $(\mathrm{n}=19)$ & Clonidine $(\mathrm{n}=15)$ \\
\hline Gender (\% male) & $79 \%$ & $40 \%{ }^{\#}$ \\
Age in years (mean \pm SEM) & $31.8 \pm 1.1$ & $28.7 \pm 1.1$ \\
Unemployment rate $(\%)$ & $58 \%$ & $100 \%$ \\
Lifetime use of opioids in years (mean \pm SEM) & $9.9 \pm 1.4$ & $7.9 \pm 1.3$ \\
Time since the last heroin administration in hours (mean \pm SEM) & $11.9 \pm 1.3$ & $12.5 \pm 2.8$ \\
Tolerance to heroin in grams (mean \pm SEM) & $3.5 \pm 0.9$ & $2.2 \pm 0.4$ \\
Number of completed detoxifications (mean \pm SEM) & $3.8 \pm 1.3$ & $3.2 \pm 0.8$ \\
Number of initiated detoxifications in the past (mean \pm SEM) & $4.2 \pm 0.9$ & $2.8 \pm 0.9$ \\
\hline
\end{tabular}

$\# p<0.05$, Fisher's exact test. 


\section{Figure legends}

\section{Figure 1.}

Summary of participant flow during the intention-to-treat study.

\section{Figure 2.}

Effects of pregabalin pretreatment on morphine-induced hyperlocomotion, i.v. self-administration of morphine, and neuroplasticity in VTA DA neurons at 24 $\mathrm{h}$ after morphine administration. (A) Treatment protocol is on the top. Cumulative locomotor activity for 90 min after injections of the vehicle (Veh) and drugs in adult C57BL/6J mice. Morphine (10 mg/kg, $\mathrm{n}=13 ; \mathrm{M} 10)$ induced clear hyperlocomotion ( ${ }^{*} p<0.05$, compared to vehicle). Non-sedative doses of pregabalin (50-200 mg/kg, i.p., $\mathrm{n}=6-16$; P50, P100 and P200) administered 30 min prior to morphine, dose-dependently attenuated the hyperlocomotion (pretreatment effect: $\mathrm{F}_{3,57}=5.7, p<0.01$, Bonferroni ${ }^{\#} p<$ 0.05, \#\# $p<0.01, \# \# p<0.001$ as compared to morphine). (B) Drug-naïve adult C57BL/6J mice were allowed to intravenously self-administer either pregabalin $(5 \mathrm{mg} / \mathrm{ml})$ or morphine $(1 \mathrm{mg} / \mathrm{ml})$ during 20 -min sessions. A positive reinforcement factor indicates positive reinforcement. In contrast to pregabalin, morphine induced a significant increase in the reinforcement factor. Pretreatment with pregabalin (50 mg/kg, i.p.) suppressed morphine self-administration (treatment factor: $\mathrm{F}_{3,50}=5.2, p<0.01$, Bonferroni ${ }^{*} p<0.05$ as compared to saline (Sal), ${ }^{\#} p<0.05$ as compared to morphine, $\mathrm{n}=6-26$ pairs of mice). SA, self-administration. (C) Dose of morphine, which was selfadministered during the 20 -min session ( ${ }^{*} p<0.05, t$-test). (D) Representative traces of AMPAR- and NMDAR-mediated currents (scale bar $=50 \mathrm{pA} / 50 \mathrm{~ms}$, 
left) and AMPA/NMDA ratios in VTA DA neurons of midbrain slices obtained ex vivo $24 \mathrm{~h}$ after the drug injection in TH-EGFP mice (Bonferroni ${ }^{* *} p<0.01$ as compared to vehicle, $n=7-8$ mice, right). Bars are means + SEMs.

\section{Figure 3.}

Effects of pregabalin treatment on naloxone-precipitated withdrawal symptoms in morphine-dependent mice. Top: treatment schedule of twice daily injections of morphine (8-45 mg/kg, s.c.), followed by naloxone ( $3 \mathrm{mg} / \mathrm{kg}$, i.p.) on the final day of the experiment, $2 \mathrm{~h}$ after the last dose of morphine. Pregabalin (50 mg/kg, i.p.; P50) or vehicle (Veh) was administered $30 \mathrm{~min}$ before the naloxone. Bottom: effects of pregabalin pretreatment on naloxoneprecipitated jumps (A), tremor episodes (B) and rears (C) during the 30 min naloxone-precipitated withdrawal ( $\mathrm{n}=9$ mice per group). Bars are means + SEMs. ${ }^{*} p<0.05, t$-test.

\section{Figure 4.}

Effects of long-term morphine exposure on pregabalin-induced place conditioning in mice and i.v. self-administration of pregabalin. (A) Study design and scheme of the 4-week escalating-dose morphine treatment, with associated weight loss. Morphine was administered at $16 \mathrm{~h}$ intervals (10-70 $\mathrm{mg} / \mathrm{kg}$, s.c.). One week after the last dose of morphine, the place conditioning paradigm was used $(\mathbf{B}, \mathbf{C})$ and, three weeks after, i.v. self-administration was used (D - F) to test for possible rewarding effects of pregabalin. (B) Expression of place conditioning to pregabalin (50 and $100 \mathrm{mg} / \mathrm{kg}, \mathrm{P} 50$ and P100), given as timeshifts between post- and pre-conditioning times spent in 
the drug-paired compartment of the apparatus in morphine-naïve (Mor_N, $\mathrm{n}=$ 12) and morphine-exposed (Mor_E, $n=6-13$ ) mice. The post-test was carried out $48 \mathrm{~h}$ after the last conditioning session. The timeshifts did not differ between groups (morphine exposure effect: $F_{1,39}=0.01, p=0.9$; pregabalin dose effect: $F_{1,39}=1.6, p=0.2$ ). (C) Locomotor activity during the four 30 -min conditioning sessions after injections of the vehicle and pregabalin. Mor_E mice were less active than Mor_N mice in the vehicle (morphine exposure effect: $F_{1,39}=44.1, p<0.001 ;$ P50 group: Mor_N vs. Mor_E ${ }^{*} p<0.01 ; \mathrm{P} 100$ group: Mor_N vs. Mor_E ${ }^{\#} p<0.01$ ) and pregabalin (morphine exposure effect: $F_{1,39}=11.8, p<0.001 ; P 100$ group: Mor_N vs. Mor_E ${ }^{\#} p<0.01$ ) sessions. (D) Nose-poke activity during a pretest prior to i.v. selfadministration (SA) of pregabalin $(5 \mathrm{mg} / \mathrm{ml})$ was similar in Mor_N $(n=25)$ and Mor_E $(n=17)$ mice $(t$-test, $p>0.05)$. The reinforcement factor for pregabalin (E) and the dose of pregabalin voluntarily self-injected (F) during 20-min SA sessions were similar in Mor_N $(n=12$ pairs $)$ and Mor_E $(n=8)$ mice (t-test, $p>0.05)$. All data are presented as means \pm SEMs, unless within the symbols.

\section{Figure 5.}

Effects of low morphine doses before pregabalin administration on persistent neuroplasticity in VTA DA neurons and place conditioning. Treatment protocol for electrophysiology is on the top; for conditioned place preference tests, pregabalin was given 30 min after each morphine dose just before the conditioning sessions. (A) Representative traces of AMPAR- and NMDARmediated currents (scale bar $=50 \mathrm{pA} / 50 \mathrm{~ms}$, left) and the AMPA/NMDA 
ratios in VTA DA neurons of midbrain slices obtained ex vivo $24 \mathrm{~h}$ after the drug injection in TH-EGFP mice. Morphine (1, 3 and $10 \mathrm{mg} / \mathrm{kg}, \mathrm{M} 1, \mathrm{M} 3$ and M10; $n=7-10$ mice) dose-dependently increased the AMPA/NMDA ratio (morphine effect: $F_{3,30}=8.9, p<0.001$, Bonferroni ${ }^{* * *} p<0.01$ as compared to vehicle). Pregabalin (50 mg/kg, P50) administered 30 min later ( $n=6-10$ mice) enhanced morphine-induced neuroadaptations (pregabalin effect: $F_{1,40}$ $=8.9, p<0.001$, Bonferroni ${ }^{\#} p<0.05,{ }^{\#} p<0.01$ as compared to corresponding morphine-alone group). (B, C) Conditioned place preference expressed as timeshifts between post- and pre-conditioning times spent in the drug-paired compartment of the apparatus at $96 \mathrm{~h}$ after the last conditioning session. (B) The timeshift of the group pretreated with morphine $(1 \mathrm{mg} / \mathrm{kg}$, M1-P50) was significantly different from the control (Veh+Sal) and pregabalinmorphine groups (50 mg/kg-1 mg/kg; P50-M1) (treatment effect: $F_{3,28}=16.7$, $p<0.01$, Bonferroni ${ }^{*} p<0.05,{ }^{* * *} p<0.001$ as compared to M1+P50). (C) The timeshift of the group pretreated with morphine ( $3 \mathrm{mg} / \mathrm{kg}, \mathrm{M} 3+P 50)$ was significantly different only from the control $(V e h+S a l)$ (treatment effect: $F_{3,35}=$ 8.5, $p<0.001$, Bonferroni * $p<0.05$ as compared to M3+P50). (D, E) Locomotor activity during the 30-min conditioning sessions after injections of the vehicle and drugs. Locomotor activity during the morning session was similar from day to day in all treatment groups and did not differ between the groups (Greenhose-Geisser test $p>0.05$ for the time $\mathrm{x}$ treatment interaction). (D) The M1+P50 group had the highest locomotor activity as compared with other treatment groups (treatment effect: $F_{3,28}=16.7, p<0.01$, Bonferroni ${ }^{*} p$ $<0.05$ as compared to Veh+Sal, and ${ }^{\#} p<0.05$ as compared to M1+P50). (E) The M3+P50 group had the highest locomotor activity as compared with other 
treatment groups (treatment effect: $\mathrm{F}_{3,28}=33.5, p<0.001$, Bonferroni ${ }^{*} p<$ 0.05 as compared to Veh+Sal, and ${ }^{\#} p<0.05$ as compared to M3+P50). Data are shown as means + SEMs.

\section{Figure 6.}

Effects of pregabalin and clonidine on opioid withdrawal in heroin abusers during the 6-day detoxification treatment. (A) The pregabalin group $(n=19)$ showed significantly higher retention levels as compared to the clonidine group $(n=15)(79 \%$ in pregabalin group vs. $47 \%$ in clonidine group, Fisher's exact test, $p=0.05$ ). (B) Pregabalin patients reported feeling better than clonidine patients on the overall health self-assessment scale. (C) The number of reported adverse effects in the pregabalin (left) and clonidine (right) groups. Pregabalin patients experienced significantly less low energy states, fatigue and tiredness than clonidine patients ( $\# p<0.05$, Fisher's exact test). (D) Intake of the NSAID ketorolac was significantly lower in the pregabalin group $\left({ }^{*} p<0.05, t\right.$-test). Pregabalin patients demonstrated lower scores in opioid craving (E), depression (F), and anxiety (G) than clonidine patients. Withdrawal scores in subjective (H), objective (I) and clinical estimation (J) remained the same in the two treatment groups. Data are shown as means \pm SEMs. Panels (A) and (E-J) were modified from (Krupitsky et al., 2016). 


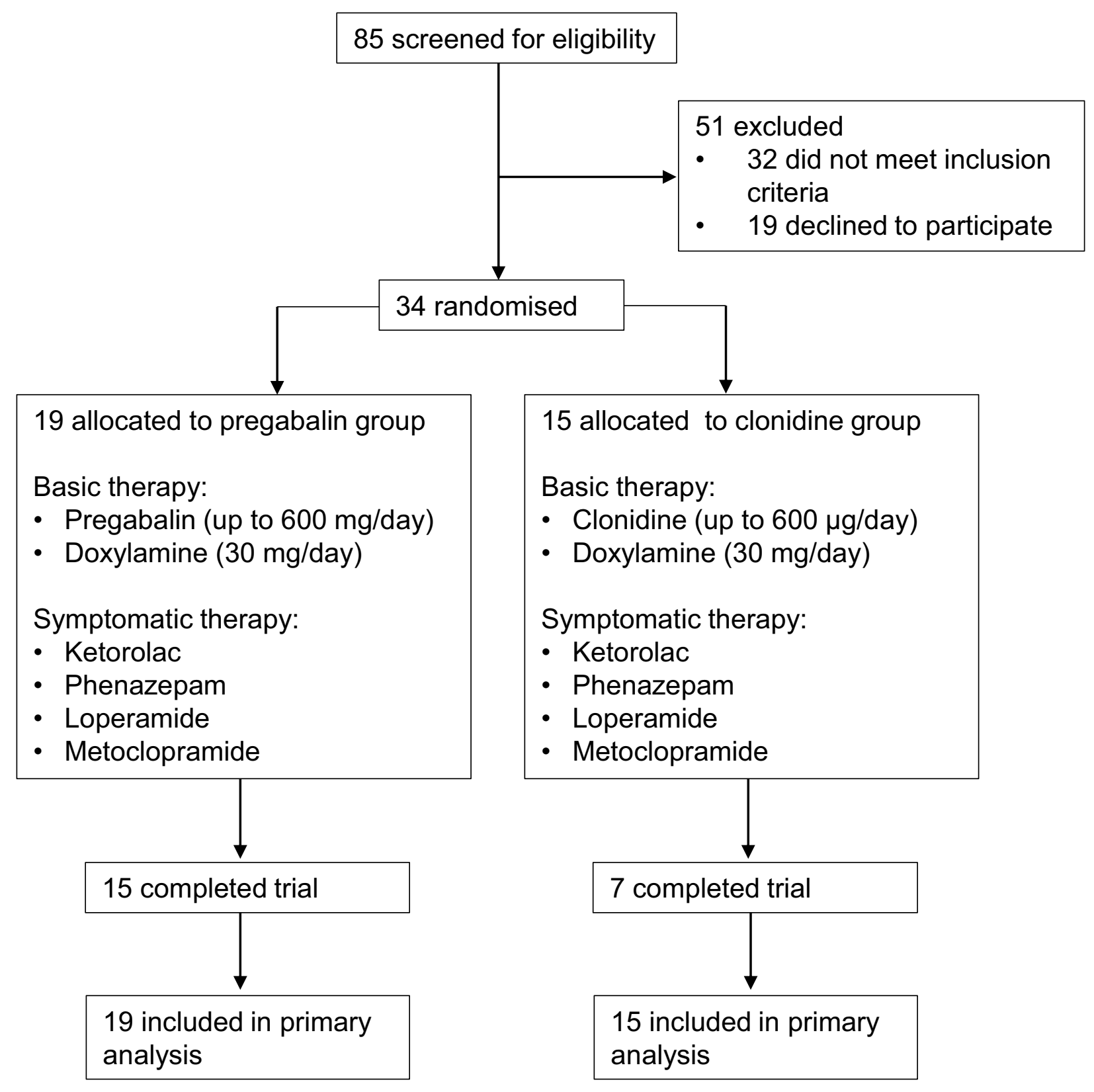



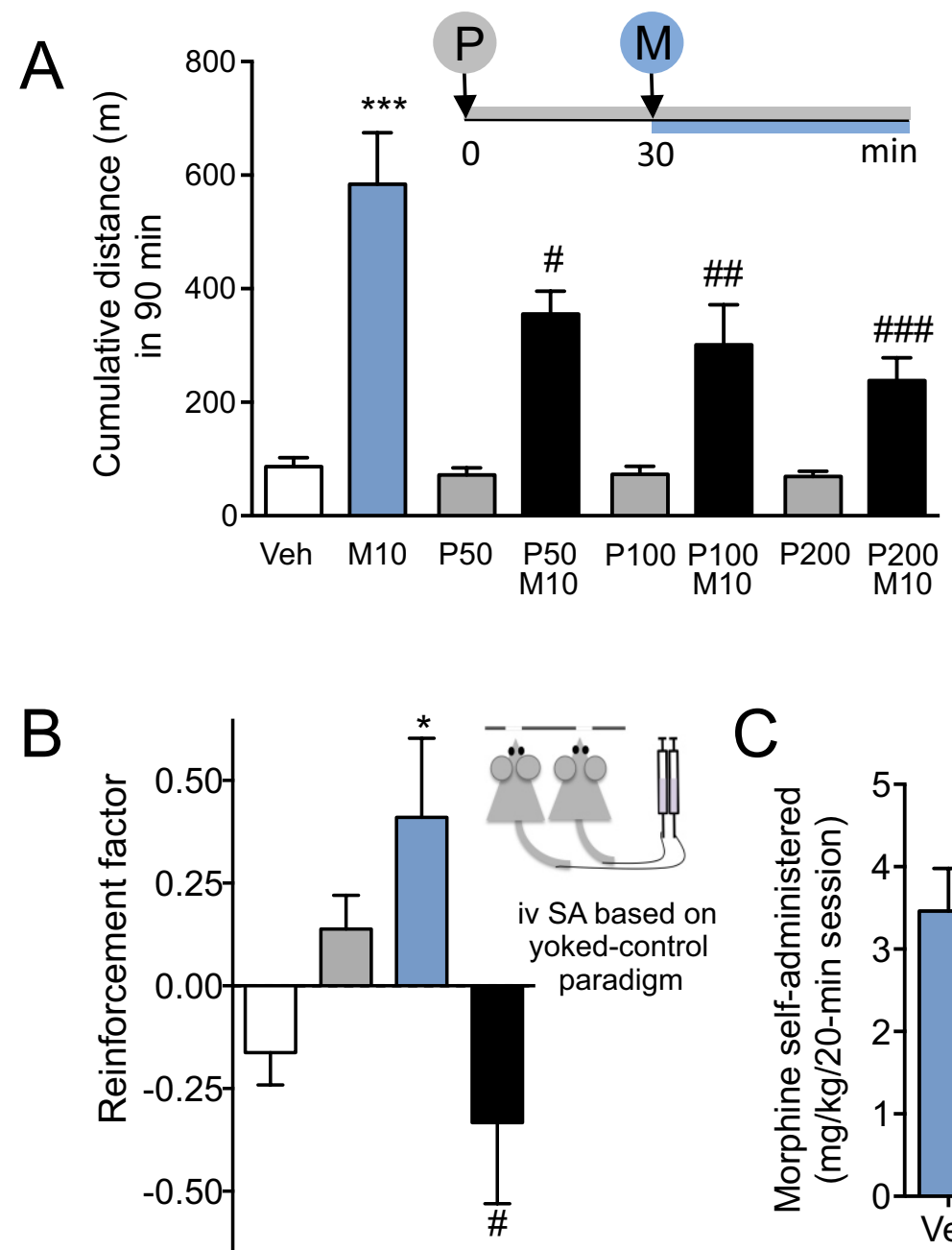

30-min pretreat: - $\quad$ - Veh P50

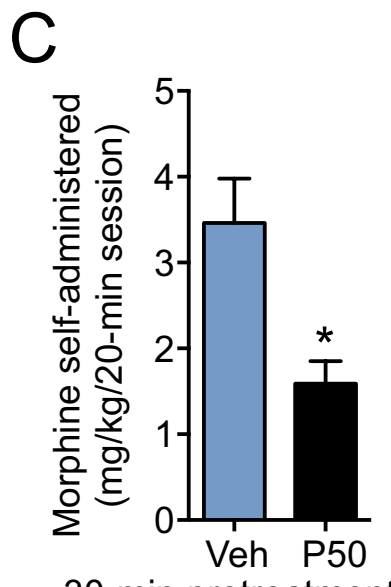

SA: Sal P M M

D
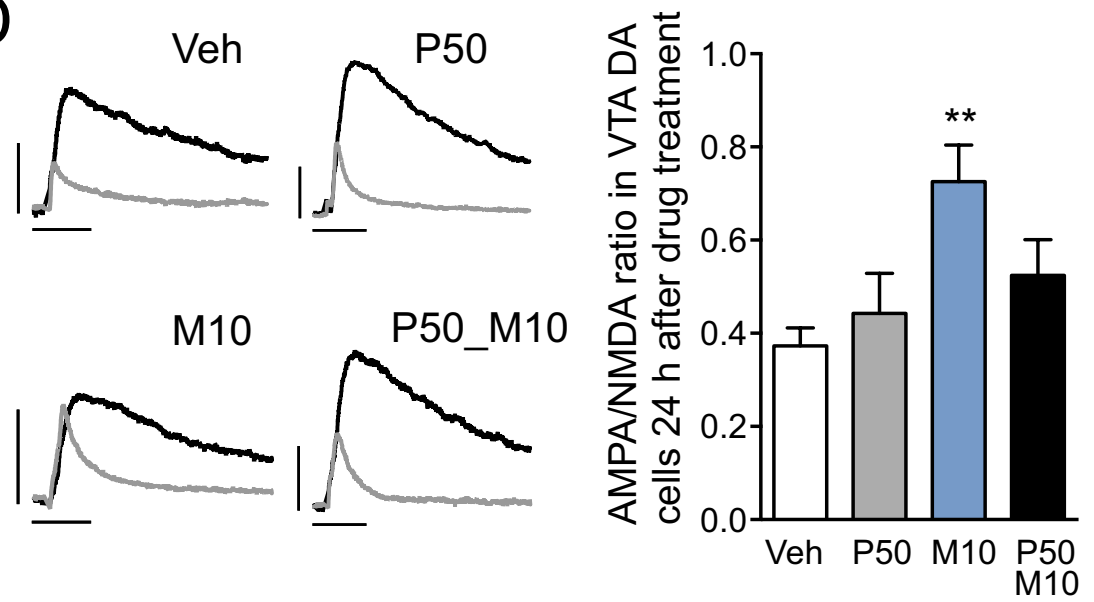


\begin{tabular}{|c|c|c|c|c|}
\hline M8 M15 & M20 M25 & M30 M35 & M40 M45 & $\mathrm{M} 45 \rightarrow \mathrm{P} 50 \rightarrow \mathrm{NLX} 3$ \\
\hline Day: 1 & 2 & 3 & 4 & 5 \\
\hline
\end{tabular}

On day 5:
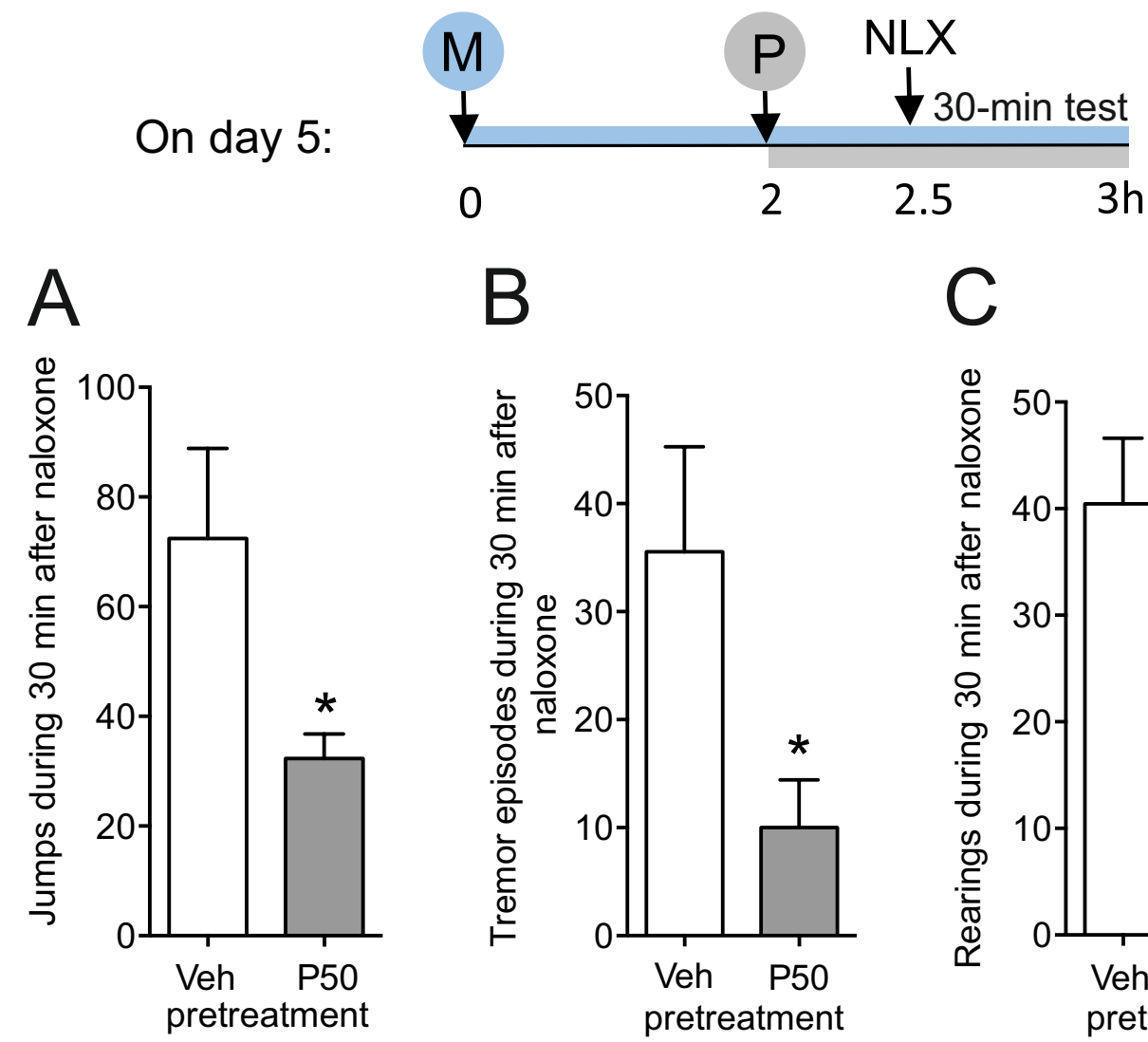

B
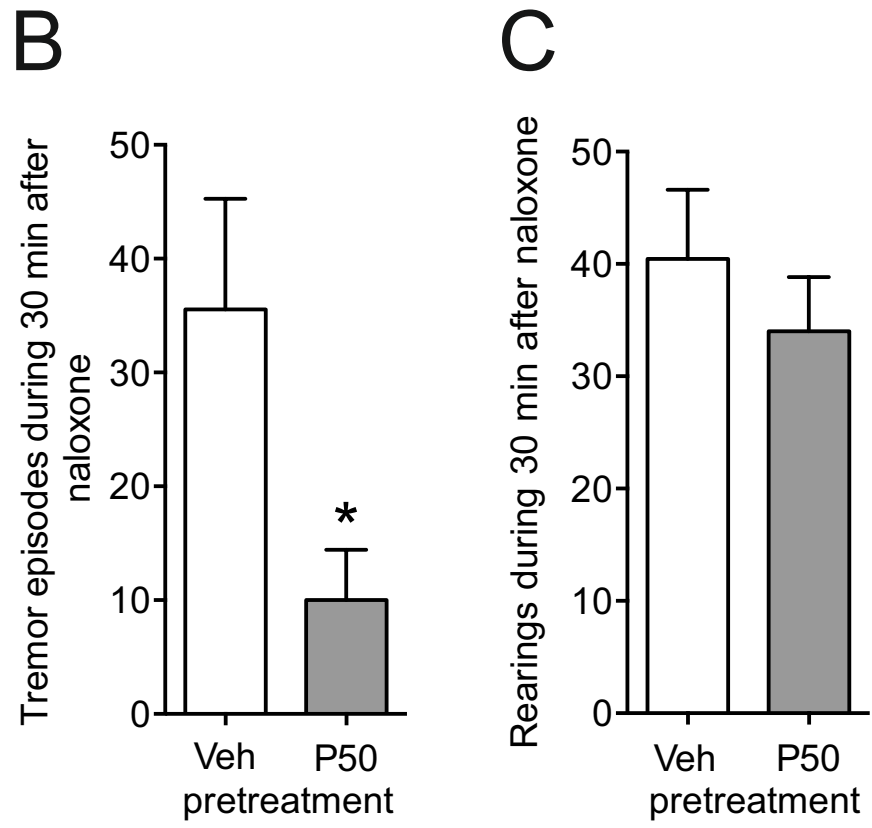

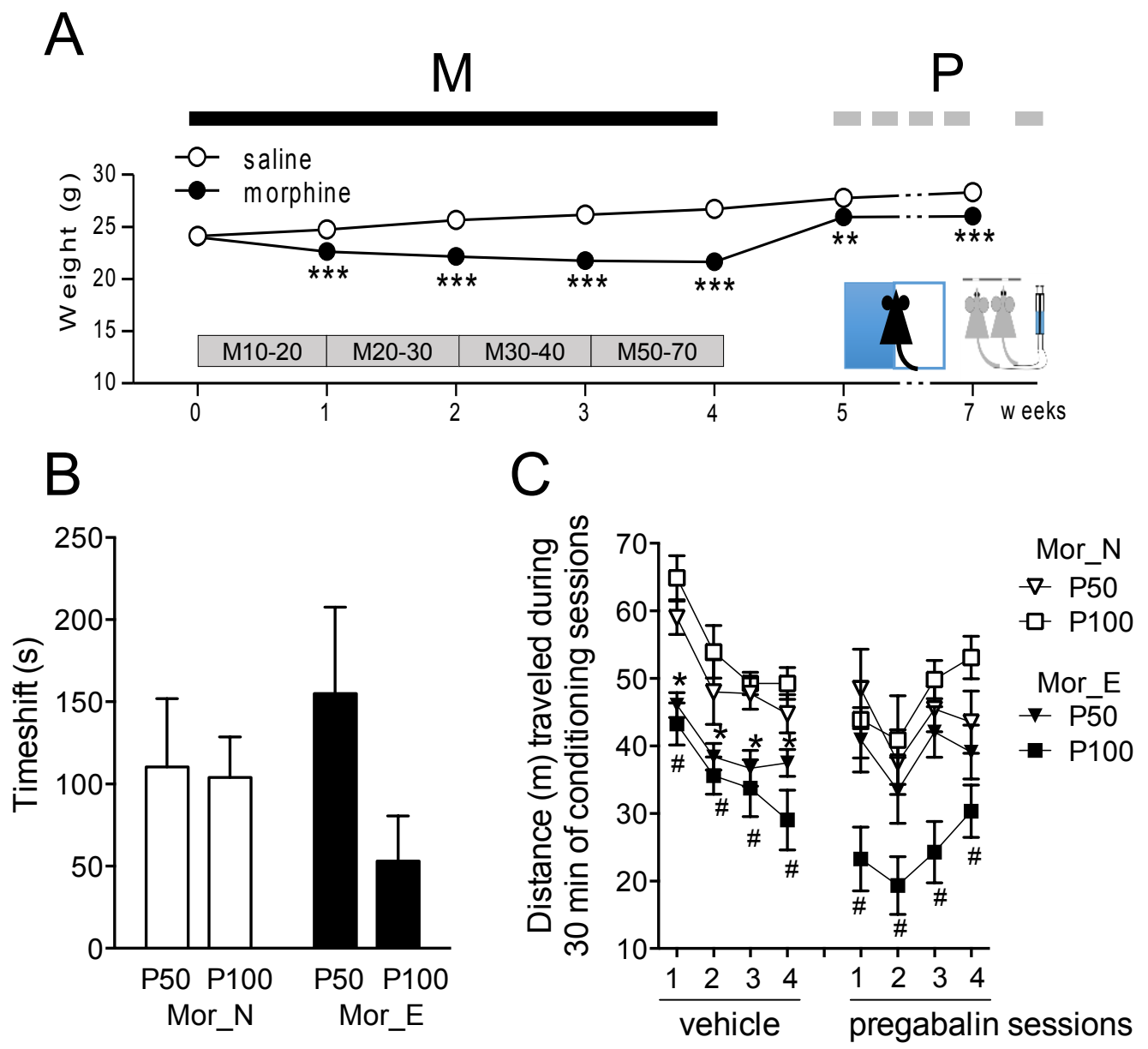

D

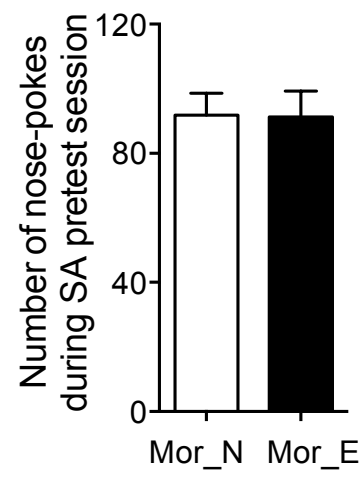

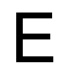

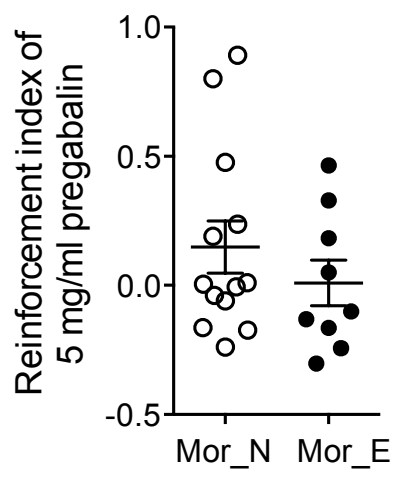

F

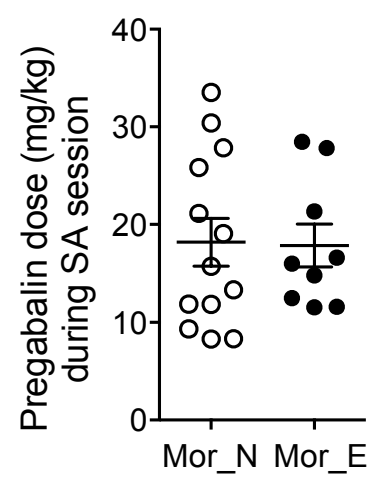




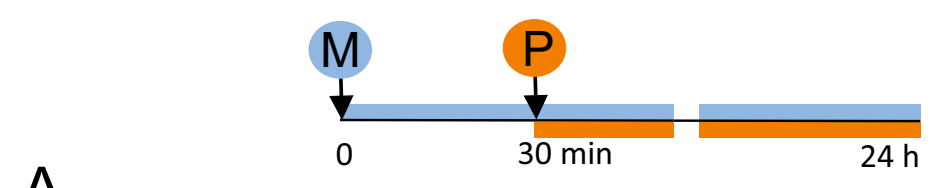

A
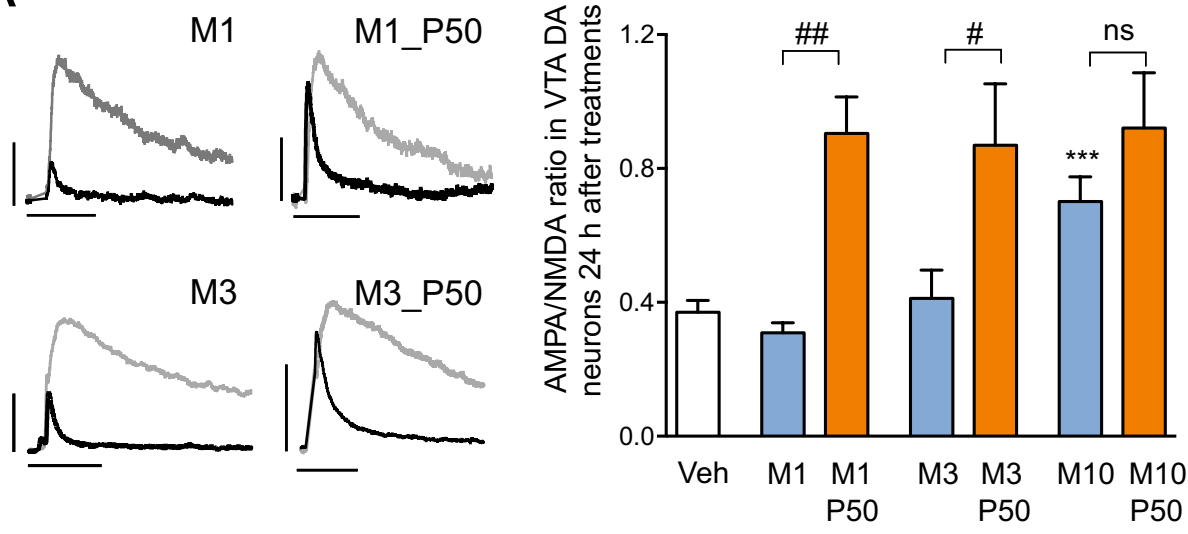

B

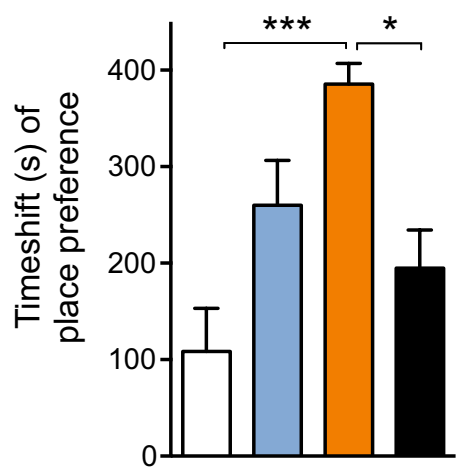

C

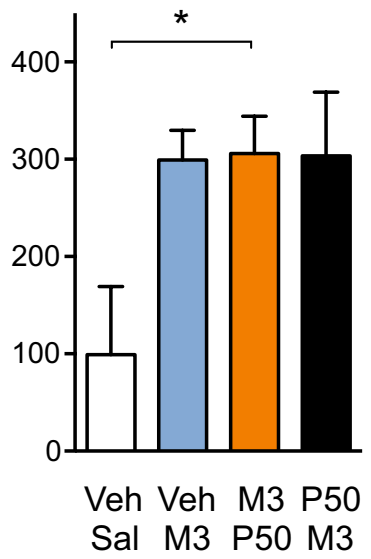

Pretreatment: Veh Veh M1 P50

Conditioning: Sal M1 P50 M1

E
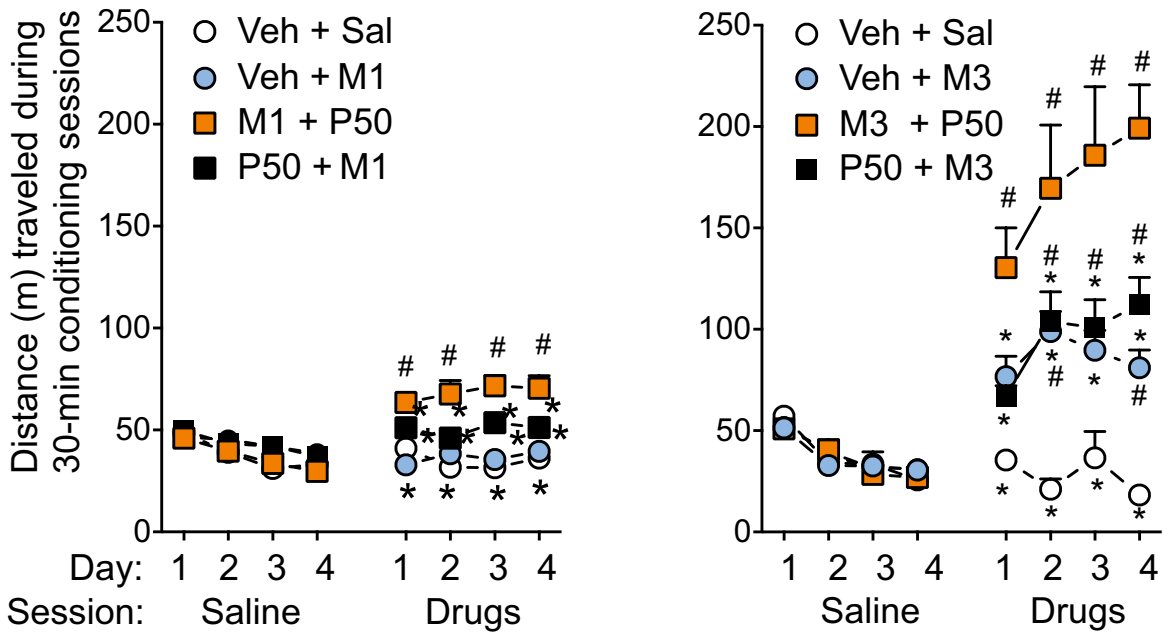
A

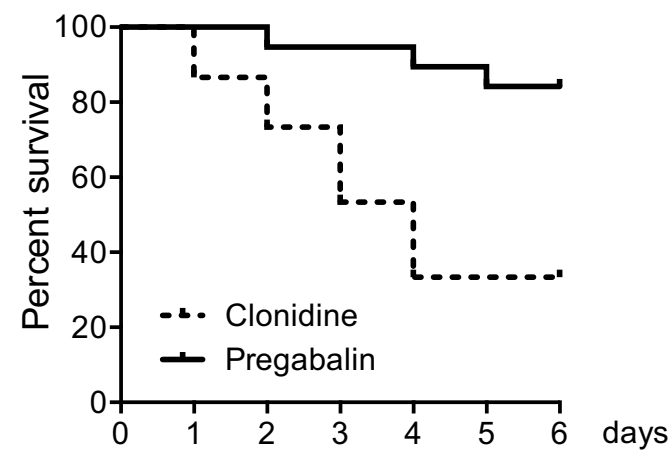

B

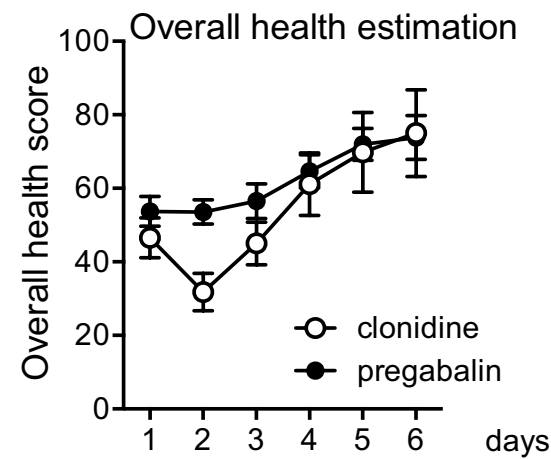

C

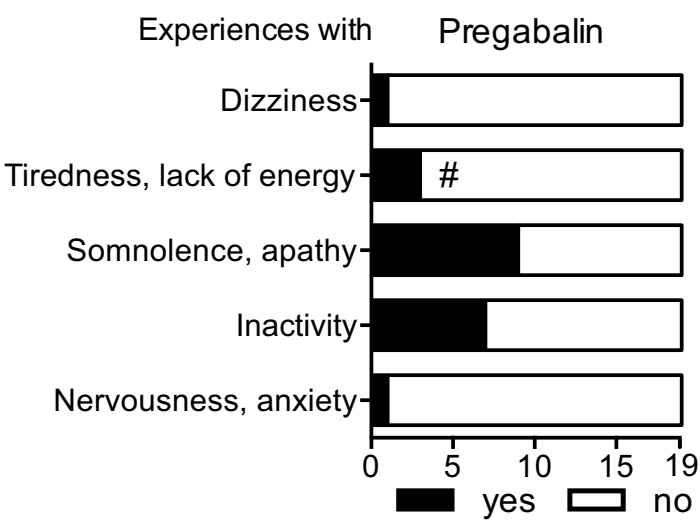

D

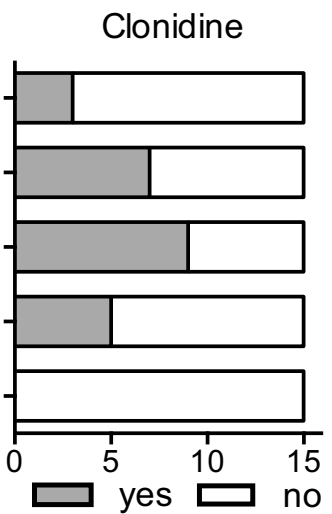

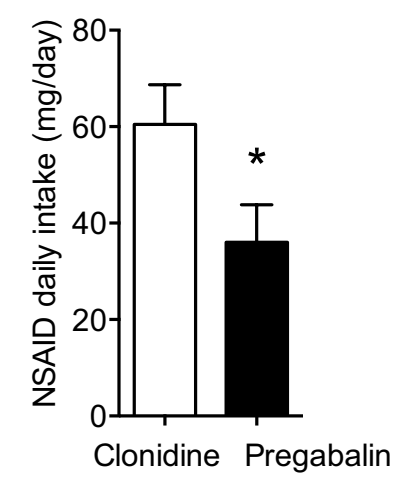

E

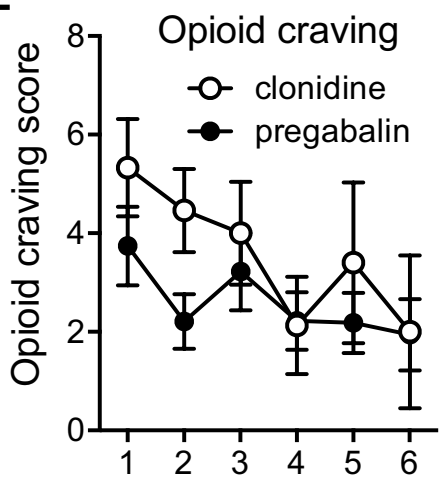

$\mathrm{H}$

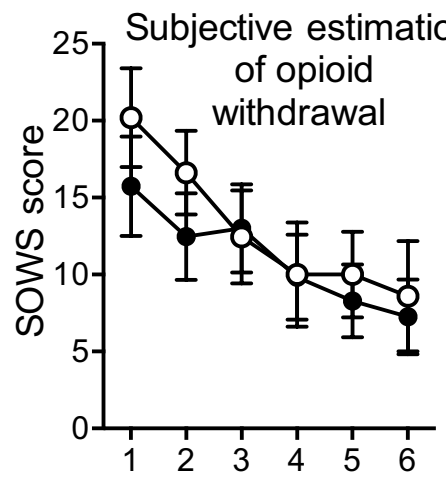

F

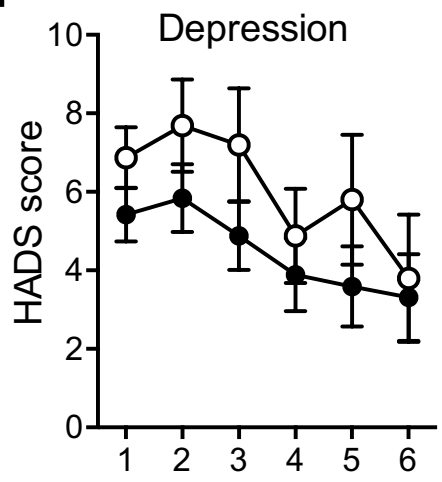

I

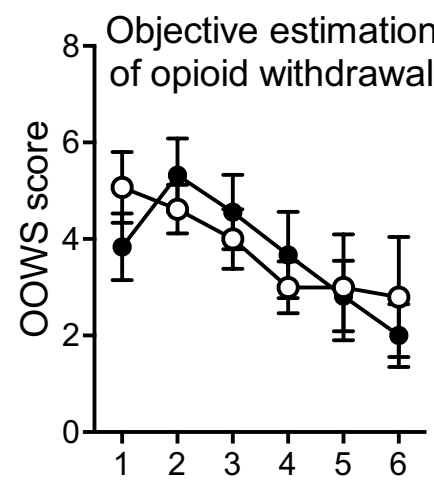

G

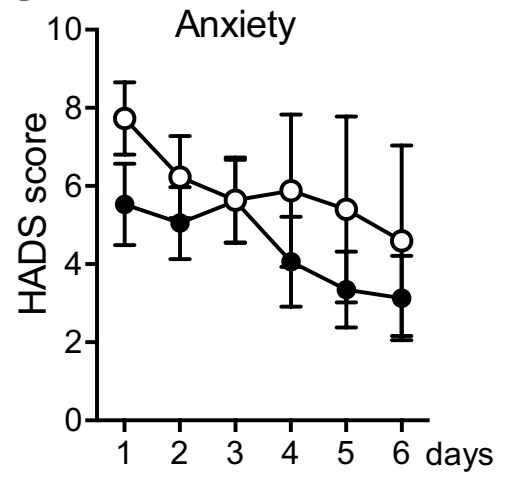

$J$

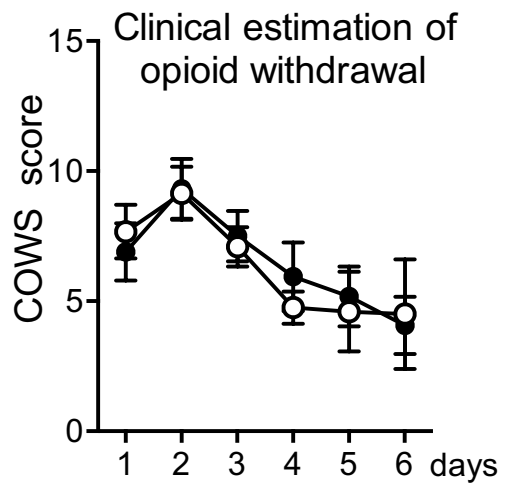

